\title{
NAS INTERMITÊNCIAS DO DIZER DO OUTRO: OLHARES SOBRE O GÊNERO EM THE BLUEST EYE, DE TONI MORRISON
}

\author{
Raimundo Expedito dos Santos Sousa é doutorando em Estudos Literários pela Universidade Federal de Minas Gerais - UFMG; \\ bolsista da Fundação de Amparo à Pesquisa do Estado de Minas Gerais - FAPEMIG; mestre em Estudos Literários pela Universidade \\ Federal de São João Del-Rey - UFSJ. \\ E-mail: raimundo_sousa@terra.com.br \\ Ederson Luís Silveira é mestrando em Linguística na Universidade Federal de Santa Catarina - UFSC; bolsista da Coordenadoria de \\ Aperfeiçoamento de Pessoal de Nível Superior-CAPES; pós-graduando em Ontologia e Epistemologia pela AVM Faculdades Associadas \\ e membro do Grupo de Estudos em Territorialidades da Infância e Formação Docente (GESTAR/CNPq). \\ E-mail: ediliteratus@gmail.com
}

Resumo: O presente trabalho visa analisar a obra The bluest eye, de Toni Morrison, a partir dos estudos pós-coloniais a fim de trazer à tona contradiscursos de resistência dos sujeitos, tendo como ponto de partida a literatura situada fora dos limites do cânone ocidental e problematizações acerca da mudez, das intermitências e da autorrepresentação das mulheres a partir das relações estabelecidas cultural e historicamente com o Outro.

Palavras-chave: mulher; estudospós-coloniais; estudos literários.
Résumé: Le présent travail vise à analyser le travail le œil plu, de Toni Morrison, des études postcoloniales afin de faire apparaître l'objet résistance contradiscursos, ayant comme point de départ la littérature située en dehors des limites du Canon occidental et problematizações sur la coupure du son, le scintillement et l'autorrepresentação des femmes de relations culturelles et historiquement établies entre eux.

Mots clés: femme; études postcoloniales; études littéraire.

\section{1) Introdução}

"Não há nada no mundo mais nu que um esqueleto", escrevera José Saramago nas Intermitências da morte, em que o enredo cerceia em torno da decisão da morte em interromper momentaneamente os falecimentos em determinado lugar fíctício. Sendo intermitente a decisão de interromper falecimentos, o sentido dicionarístico da palavra intermitência nos leva a supor que a intermitência é uma interrupção momentânea. Dessa forma, no romance de Saramago, a qualquer momento, a morte pode voltar a realizar seu trabalho. O presente trabalho não é sobre a morte, tampouco sobre a ficção de Saramago, mas sobre as intermitências do dizer que emergem a partir da análise de produções literárias sob o viés da crítica pós-colonial. Como essa vertente crítica emerge no seio dos contextos britânicos de colonização, interessa aos estudos abrigados sob este guarda-chuva teóricoepistemológico trazer à tona contradiscursos de resistência dos sujeitos colonizados e partir da análise de literaturas que destoem dos cânones tradicionais. A partir disso, cabe acentuar o silenciamento das mulheres percebidas enquanto subalternas, porque propositalmente deixadas de lado a partir daquilo que Neves \& Almeida (2014) chamaram de duplo silenciamento: 
O colonialismo promove a despersonalização do ser colonizado, e nesse processo, o ser colonizado é também silenciado, ou seja, não lhe é permitido que se autorrepresente, sendo que sua representação é feita sempre pelo Outro colonizador. Há um elemento ainda mais grave nesse processo de silenciamento do subalterno, que é a questão de gênero dentro da própria empresa colonial, pois a mudez da mulher colonizada é ainda mais preocupante, já que esta é duplamente silenciada, subordinada tanto pelo patriarcado quanto pelo colonialismo. (NEVES \& ALMEIDA, 2014, p. 71)

Devido ao fato de a experiência dos povos dominados pelo império britânico por mais de 350 anos estar sendo escrita por autores ex-colonizados e, mais ainda, residentes nas ex-metrópoles coloniais, a voz desses subalternos não deixa de fazer emergir as históricas e culturais tentativas de silenciamento - intermitências constantes do dizer - que estes sofreram (e sofrem) com o passar do tempo. Neste contexto, cabe acentuar, então, que a temática da diversidade étnica nos Estados Unidos tem suscitado, nas últimas décadas, uma profusão de produções culturais em diversos âmbitos da arte, como o cinema, a música e a literatura. Embora, de acordo com McClintock (1992), o termo "pós-colonialismo" possa aceitar diversas acepções, os estudos pós-coloniais convergem para

[...] um conjunto de estratégias interpretativas voltadas para a rica diversidade de práticas culturais que caracterizam as sociedades colonizadas ou egressas da colonização europeia, desde o momento inicial da colonização, no alvorecer da modernidade [...] até o presente. (TOLLER GOMES, 2006, p. 01)

De fato, após um histórico de discriminação e exclusão social, vários grupos vêm ganhando força nas últimas décadas, dentre eles os afro-descendentes e as mulheres. Com isso, questões relativas a tais grupos passaram a ser discutidas nas universidades, de modo que diversos estudos sobre tais minorias vêm sendo realizados em diferentes áreas do conhecimento. Especificamente na literatura, com a ascensão dos Estudos Culturais e PósColoniais, cresce o interesse em estudar obras literárias produzidas por escritores marginalizados do cânone literário eurocêntrico.

Nesse sentido, escritores de origem pós-colonial, advindos de minorias étnicas, têm sido resgatados em estudos acadêmicos e conquistado seu espaço no mercado editorial, o que evidencia a necessidade de se rever os parâmetros definidores de alta literatura, na medida em que nomes como Michael Ondaatje, Derek Walcott, Alice Walker e Toni Morrison, dentre vários outros, têm recebido, finalmente, a devida atenção como produtores de literatura em língua inglesa, status antes conferido apenas a escritores "canônicos", herdeiros de Shakespeare, Milton e Jane Austen.

Quanto às mulheres escritoras, especialmente as de origem pós-colonial, a luta pela inserção no meio literário tem sido, indubitavelmente, ainda mais árdua, pois o cânone literário não é apenas eurocêntrico, conforme afirmado acima, mas também falocêntrico, isto é, centrado na figura masculina. Durante séculos esquecidas da historiografia literária, 
escritoras de diversos países e gerações têm sido resgatadas dos escombros do silenciamento, graças ao empenho do movimento feminista a partir da década de 1960 .

Se, no início do século XX, Virginia Woolf afirmava, em uma de suas várias considerações perspicazes, que a mulher escritora precisa, para produzir literatura, de um quarto com chave e dinheiro para seu sustento (WOOLF, 1970), o que dizer das mulheres vitimadas pela desigualdade social, pela opressão cultural e pelas desigualdades de gênero que, ainda assim, almejassem transpor para o papel seus sonhos, amarguras e (des)esperanças?

Ora, podemos afirmar, em uma perspectiva gradativa, que as mulheres de etnias ou classes desprivilegiadas enfrentaram - e ainda enfrentam -, mais do que homens de origem pós-colonial e do que as mulheres brancas, um enorme desafio pela inserção e aceitação em um campo literário sobremaneira excludente. Sob essa perspectiva, este artigo tem como objeto de estudo a primeira obra literária de Toni Morrison, escritora afro-estadunidense, intitulada The Bluest Eye, cuja primeira publicação data de 1970.

Ao constituírem um campo frutífero de investigação das relações sociais, culturais e étnicas balizadas pelas questões de gênero, os estudos de gênero apresentam importantes afinidades teóricas e críticas com os estudos pós-coloniais, e a intersecção entre ambos os campos epistemológicos permite, na relação do texto literário com suas condições históricas e sociais de produção, uma mais análise abrangente e complexa. Nesse sentido, este trabalho objetiva analisar, à luz dos estudos pós-coloniais em articulação com os estudos de gênero, como o romance de Toni Morrison relaciona, sob uma perspectiva notadamente feminista, a questão ideológica. Interessa verificar, na obra em análise, de quais maneiras as ideologias de gênero, classe e etnia interpelam os sujeitos a ocuparem determinados papéis e a seguirem determinada conduta, bem como perscrutar quais conflitos decorrem dessa interpelação na sociedade estadunidense, sobremaneira racista, classista e patriarcal, representada em The Bluest Eye.

\section{2) A etnia como ideologia e a discriminação étnica nos Estados Unidos em meados do século XX}

Para uma melhor compreensão do romance de Toni Morrison, faz-se importante levar em consideração as condições de produção da obra. Nesse sentido, importa considerar que The Bluest Eye foi escrito por uma escritora afro-descendente em um momento histórico - década de 1960 - marcado por tensão étnica nos Estados Unidos.

Embora a discriminação contra os negros nos Estados Unidos remonte ao período colonial, no século XX, com o Movimento Pelos Direitos Civis, tem-se o recrudescimento do conflito étnico devido à revolta generalizada, por parte dos afro-descendentes, ante as condições desumanas que lhes eram impingidas na sociedade estadunidense. Evidentemente, tal luta por direitos civis partiu de uma intelligentsia letrada, que assumiria a incumbência de falar por aqueles que não tinham direito de se expressarem. A gênese de 
tal conflito ocorreu nos idos de 1930, quando houve um grande movimento migratório de afro-descendentes para o norte do país, o que deixou a comunidade branca amedrontada e gerou a formação de guetos negros nas regiões periféricas das grandes cidades.

De acordo com Brogan (1985), em contraposição às discriminações étnicas, o Movimento Pelos Direitos Civis consistiu em um marco na recente história dos Estados Unidos, mobilizando milhões de pessoas, majoritariamente afro-descendentes, através de protestos, passeatas e greves, a fim de abolir da constituição daquele país as leis que instauraram a segregação racial.

Ainda segundo o autor, em dezembro de 1955, por exemplo, a prisão de Rosa Parks, por ter se recusado a ceder seu assento no ônibus para um homem branco, subvertendo a hierarquia racial, deflagrou o Movimento de Boicote aos ônibus de Montgomery, Alabama. Tal movimento, liderado pela "Southern Christian Leadership Conference" (SCLC), cujo organizador era Martin Luther King Junior, perdurou de 5 de dezembro de 1955 a 21 de dezembro do ano seguinte, quando foi decretado o fim da segregação racial nos ônibus. Considerado por muitos historiadores como o primeiro grande passo rumo à conquista dos direitos civis, o Boicote de Montgomery destacou-se também por ter revelado aos Estados Unidos e, posteriormente, ao mundo, a figura de Martin Luther King.

Estimulados pela vitória do movimento de boicote aos ônibus de Montgomery, em 1960 estudantes negros começaram a sentar-se em restaurantes, lojas, bibliotecas e demais lugares onde negros não eram atendidos e lá ficavam, pacificamente, aguardando atendimento. Devido a tal atitude, diversos afro-estadunidenses, dentre eles Martin Luther King, foram presos. Em contraposição à prisão do líder, entraram em cena John F. Kennedy, então candidato à presidência dos Estados Unidos, e seu irmão Robert Kennedy. Somente após a intervenção dos dois irmãos Martin Luther King foi libertado.

A repressão violenta a movimentos como esse, liderada pela comunidade branca, teve repercussão muito grande e, dessa maneira, o confronto deixou de ser um problema doméstico para transformar-se em tema de noticiários em todo o mundo. Por fim, a Suprema Corte dos Estados Unidos declarou ilegal a segregação racial nos ônibus interestaduais e estações rodoviárias.

Já em 1962, tanques de guerra e centenas de tropas federais foram enviados à Universidade do Mississipi para garantir a entrada de um estudante negro em seus domínios. Apesar de estar legalmente amparado, o calouro só conseguiu entrar na instituição e assistir aulas sob escolta de soldados das tropas federais. Em junho de 1963, por sua vez, o presidente John F. Kennedy teve que ordenar a mobilização da Guarda Nacional do Alabama para garantir a matrícula de dois estudantes afro-descendentes na Universidade Estadual, visto que o governador daquele estado chegara ao extremo de tentar bloquear, pessoalmente, a entrada dos estudantes no prédio da universidade.

A tensão emocional causada por todos esses conflitos atingiu o ápice em 1968, com o assassinato de Martin Luther King, em Memphis, por um homem branco. O abatimento e a tristeza provocados por sua morte desencadearam uma onda de destruição que atravessou o país. Paradoxalmente, a onda de violência gerada pelas relações desiguais entre negros e 
brancos, principalmente aquela liderada pelo movimento "Black Power", teve um efeito positivo: os afro-descendentes passaram a sentir orgulho de sua etnia. Acompanhando essa nova fase de auto-afirmação, roupas africanas começaram a ser usadas e os cabelos passaram a ser penteados no estilo africano.

É nesse contexto repleto de tensões, questionamentos e redefinições vivenciadas pela sociedade que a literatura afro-estadunidense ganha impulso. Obras como Marked by Fire, de Joyce Carol Thomas, Meridian, de Alice Walker, The Bluest Eye, de Toni Morrison, e I Know Why the Caged Bird Sings, de Maya Angelou, são alguns exemplos de romances que não só apresentam e discutem experiências como o racismo e a opressão sofridos pelas mulheres como também questionam o papel dos afro-descendentes na sociedade.

Nesse sentido, desempenharam um papel preponderante para a mobilização social escritores afro-estadunidenses que, ao levantarem questões de etnia, classe e gênero em suas obras, desenvolviam um trabalho relevante no processo de construção da identidade cultural dos afro-descendentes. Portanto, a análise de sua produção literária há que levar em conta tais aspectos, pois dialoga intimamente com seu contexto de produção.

Embora nao partamos de uma posição reducionista que concebe a literatura como reprodução da realidade, sob o prisma dos Estudos Culturais, as condições de produção e recepção dizem muito para o entendimento de uma obra enquanto produto cultural, conforme se depreende da afirmação de Williams (apud CEVASCO, 2001, p. 49):

Não é possível entender um projeto artístico ou intelectual sem entender também a sua formação; a relação entre projeto e formação é sempre decisiva, e a ênfase dos estudos culturais é que justamente levar em conta os dois, sem se especializar em um ou outro.

De acordo com Bonnici (2000), é por meio das obras literárias que os antigos povos colonizados recuperam a voz que lhes havia sido negada no período colonial. Dessa forma, se o pós-colonialismo é uma teoria que estuda a descolonização das culturas e literaturas das antigas colônias, efetuada por meio do desmantelamento dos códigos europeus, bem como da subversão das ideias e valores impostos, podemos considerar o texto de Morrison como pós-colonial e, dessa forma, analisá-lo como tal.

Nesse sentido, procuramos observar como a autora, em especial no tocante às questões de gênero, subverte os valores dominantes, pois, conforme apontam Ashcroft et al (2002), a descolonização é um processo que invoca uma dialética entre sistemas centristas hegemônicos e sua subversão periférica. Ainda segundo os autores, as inversões póscoloniais das formações imperiais subvertem ou invertem o dominante para questionar os fundamentos de ontologias e sistemas epistemológicos que veriam tais estruturas binárias como inescapáveis. Portanto, analisaremos o texto de Toni Morrison como meio de expressão, questionamento, debate e contestação de uma minoria étnica em uma sociedade na qual a alteridade é sobremaneira oprimida. 


\section{3) A beleza como ideologia: o protótipo normativo de feminilidade e a exclusão de minorias étnicas na sociedade estadunidense}

Nesse diálogo da produção literária com seu contexto de produção, um aspecto chama especial atenção: a questão do gênero ${ }^{1}$. Vale destacar que adotamos, neste estudo, o conceito de gênero (atributo sócio-cultural) em vez de sexo (caráter biológico, determinista), uma vez que as diferenças sexuais, de personalidade, de papéis e de exercício de poder resultam de condicionamentos sociais (BUTLER, 1990). Daí a famosa citação de Beauvoir (1967, p. 09): "Ninguém nasce mulher, torna-se mulher". Citação que, aliás, atrevemo-nos a retificar: "ninguém nasce mulher (ou homem), é 'tornado". Sim, pois a construção da feminilidade ou masculinidade normativa se dá de fora para dentro, ou seja, é imposta ao indivíduo por uma sociedade balizada por determinadas ideologias.

Nesse contexto de tensão social e étnica, as relações de gênero, tantas vezes ignoradas, foram abordadas por escritoras afro-americanas como Toni Morrison em The Bluest Eye e em diversas outras obras posteriores, cujo tratamento extrapolaria o escopo deste trabalho. Vale lembrar que Toni Morrison, cujo verdadeiro nome é Chloe Anthony Wofford, foi a primeira afro-estadunidense a ganhar o Prêmio Nobel de Literatura, em 1993. A autora, advinda de uma família de Lorain, Ohio, que sempre preservou e valorizou a cultura negra, também foi a primeira afro-descendente a estudar em escola para brancos.

Segundo Rigney (1991), Toni Morrison, em sua intersecção entre raça e gênero, representa uma subversão da ordem falocêntrica. Ao se valer de um estilo próprio, de uma linguagem peculiar, ela escapa ao mainstream masculinista, subvertendo restrições ideológicas da tradição literária ocidental e modificando ditames patriarcais. De fato, Morrison dá voz, ainda que em termos representacionais, a mulheres tradicionalmente enunciadas por uma voz masculina que se fazia passar pela feminina.

De fato, Toni Morrison aborda temas importantes acerca da condição feminina em uma sociedade falocêntrica, na medida em que as questões de desigualdade de gênero perpassam toda sua obra. Se o conceito de gênero, de acordo com Marodin (1997), remete a uma gama de aspectos psicológicos, sociais e culturais de feminilidade ou masculinidade, características naturalizadas como masculinas ou femininas, mas designadas pelos padrões da estrutura social vigente num determinado tempo e espaço, então o gênero determina quais papéis devem ser desempenhados pelo homem e pela mulher, bem como a posição do homem como dominante e a da mulher, no mais das vezes, como subordinada.

Nesse sentido, o conceito de gênero está intrinsecamente atrelado ao de ideologia, que, de acordo com Althusser (1996), constitui um sistema de suposições pelo qual uma sociedade opera, e manifesta-se pela maneira com que nos representamos uns aos outros e somos representados. Assim, uma ideologia sexual determina, por exemplo, que tipo de

\footnotetext{
${ }^{1}$ Têm-se, em inglês, as formas genre (gênero literário) e gender (atributo sócio-cultural de relação homem/mulher), ao passo que no português o termo gênero abarca ambas as conotações.
} 
comportamento feminino, masculino ou homossexual é socialmente aceito. Portanto, a ideologia é aqui concebida como um modo de pensamento disseminado por aparelhos ideológicos (tais como Igreja, escola e família), que operam no sentido de reprimir que não deve ser reprimível e isolando o que não deve ser isolado, produzindo, assim, soluções falsas para as contradições existentes em uma dada cultura. Neste contexto, de acordo com Silveira (2013, p. 04), "Althusser complementa a teoria marxista, na medida em que defende a existência não apenas de aparelhos repressivos de Estado, mas de Aparelhos Ideológicos de Estado". Então, “esses aparelhos atuam para manutenção do sistema a partir daquilo que Bourdieu chamou de violência simbólica, em instâncias não reconhecidas pelos dominados, ações são tomadas para que se mascare a perpetuação da hierarquia estipulada pelos dominantes". (SILVEIRA, 2013, p. 07).

Apesar da influência das estruturas ideológicas de representação dos indivíduos, situam-se, subversivamente, com o passar do tempo, diferentes modos de perceber a alteridade a partir do estranhamento e da diferença. Por meio de seus textos, muitas escritoras procuram desconstruir certos papéis sociais atribuídos à mulher ao longo da história, em um processo de ampliação dos universos femininos que estiveram sempre atrelados aos domínios do doméstico e da família. Partindo da afirmação de Larrosa \& Kohan (2002), de que é a experiência que dá sentido à escritura, cabe assinalar, sob a égide do escopo investigativo que o presente trabalho se propõe, que muitas são as experiências que vão produzindo sentidos e significações outras como espaços percorridos através de novas subjetivações descentralizadoras em relação aos cânones tradicionais eurocêntricos.

Nesse sentido, é preciso ressaltar, mais uma vez, a importância dos textos literários produzidos por mulheres, que possibilitam a construção de novas identidades femininas, a partir de uma negação dos estereótipos atribuídos à mulher. Esse processo torna-se importante na medida em que contribui para o entendimento das novas relações sociais, favorecendo uma maior aceitação da idéia de complementaridade entre os gêneros.

Em ratificação à ideia da escrita feminina/feminista como eminentemente subversiva, Gilbert and Gubar apontam a necessidade de a mulher escritora contribuir com seu dízimo no sentido de desconstruir representações masculinas equivocadas. Segundo as críticas, é

[...] through the violence of the double that the female author enacts her own raging desire to escape male houses and male texts, which at the same time it is through the double's violence that this anxious author articulates for herself the costly destructiveness of anger repressed until it can no longer be contained. (GILBERT \& GUBAR, 2000, p. 85).

De fato, segundo Woodward (2000), as identidades são fabricadas por meio da marcação da diferença, que ocorre tanto por meio de sistemas simbólicos de representação quanto por meio de formas de exclusão social. A identidade, portanto, não é o oposto da diferença: a identidade depende da diferença. Nesse sentido, a construção da identidade 
feminina normativa tem-se assentado, desde a ascensão do cristianismo, religião notadamente androcêntrica, sobre duas posições binárias que não deixam margem para uma terceira via: ou a mulher é honrada - e isso inclui, evidentemente, ser passiva, abnegada e submissa -, em observância ao modelo mariano de feminilidade normativa, ou é pecadora, associada a Eva, personagem responsabilizada pela queda e expulsão da humanidade do Paraíso.

Embora o livro de Morrison forneça subsídios para se discutir uma infinidade de temas, abordaremos, devido à brevidade do trabalho, a questão da imposição ideológica associada, especificamente, à beleza, na medida em que tal aspecto nos permite discutir, simultaneamente, questões de gênero, classe e etnia. Nesse sentido, tomamos como ilustração do protótipo de feminilidade normativa estadunidense a figura da boneca Barbie. Embora tal figura não esteja associada diretamente a The Bluest Eye, a boneca exemplifica claramente a questão da ideologia de beleza, que constitui uma das temáticas mais pungentes do livro.

Del Priore (2001) aponta como a boneca tem representado, ao longo de décadas, um excludente padrão de beleza estadunidense - padrão não raro importado por suas colônias culturais, onde a realidade étnica é totalmente incompatível com tal padrão. Fisicamente, a autora aponta como o físico de Barbie constitui-se como um impiedoso modelo normativo de feminilidade: "pernas longas, cintura de pilão, traços delicados, cabelos sempre lisos e louros, seios fálicos como foguetes" (op. cit., p. 47). Ao discorrer sobre a diferença entre a boneca loira e sua amiga Christie, Del Priore é enfática ao apontar o funcionamento da ideologia racial embutida na relação aparentemente inocente entre as duas bonecas:

A caricatura étnica da boneca "morena" só faz acentuar o ideal normativo, em que os traços raciais e outros atributos são apagados. Christie, a amiga negra, não representa a diferença, mas alguém que, diante da loura, está fora da norma. Norma que só satisfaz, sublinhe-se, no narcisismo, no cuidado com a aparência, numa feminilidade sem falhas (...) Barbie faz pensar numa geração de mulheres clonadas, perfeitas, incompatíveis com a realidade social... (op. cit, p. 47).

De Lauretis (1987), por sua vez, aponta que a personagem Barbie atua ideologicamente ao destoar da função pueril esperada de uma boneca: em vez de ser um bebê tradicional, que, também ideologicamente, subsidiaria a construção de uma identidade maternal em meninas desde a tenra infância, Barbie é uma boneca adulta que, às voltas com a moda e futilidades, constitui uma ferramenta que corrobora a tecnologia ideológica do gênero, corrspondendo a um modelo didático de feminilidade, sexualidade, enfim, normas de conduta para o gênero feminino como garantia de aquiescência social.

De fato, a feminilidade associada à corporeidade e, mais especificamente, à beleza física tem sido enfatizada ao longo dos séculos, mais recentemente a partir do século XIX, quando se tornou moda "brindar" o gênero feminino como o "belo sexo", como que para esvaziá-lo de outros atributos. Tentadora e desafiadora, sagrada e profana, a feminilidade corpórea permanece, ao logo dos tempos, um paradoxo não resolvido. Desse modo, a 
ditadura da beleza é enfatizada, mais recentemente, após a disciplinarização dos corpos, isto é, quando o corpo, ao se constituir como assunto público, é regulado por regras ideológicas que o sexualizam, dessexualizam, sacralizam, adoecem, idealizam, etc (FOUCAULT, 1980). Com isso, forja-se um horizonte de expectativas, muitas vezes impossível de se alcançar, em relação à aparência física.

Com base nas exposições acerca de ideologias étnicas e de gênero, propomo-nos, doravante, a empreender uma análise de The Bluest Eye, no qual a autora desafia os padrões de beleza feminina ocidental, em sua demonstração de que o conceito de beleza é um construto social.

\section{4) Ideologia, etnia e gênero em The Bluest Eye}

Se o branco se constitui como o padrão de "beleza americana", então o valor do negro é diminuído. No entanto, o romance de Morrison trabalha no sentido de subverter tal tendência. Ao demonstrar o orgulho de ser negra, a escritora não só retrata imagens positivas da mulher negra, mas também focaliza os danos que as personagens afrodescendentes sofrem através da construção ideológica de feminilidade normativa em uma sociedade sobremaneira racista.

Logo no início do romance, a descrição quase paródica (em forma de cartilhas escolares), de uma família branca em que Dick and Jane, juntamente com seus pais, vivem confortavelmente em uma atmosfera familiar idealizada, aponta o ideal de família estadunidense. Podemos considerar a cena enunciada por esse pequeno texto introdutório como representação do conceito de família hegemônico e excludente, através do qual a cultura dominante reproduz sua superioridade hierárquica. De fato, o romance é todo centrado na esfera familiar, que, em sua atuação como aparelho ideológico, determina a procedência e o valor de cada indivíduo, o que pode ser confirmado em expressões corriqueiras como "fulana é moça de família" e "ele é de boa família".

Isso ilustra um aspecto central do funcionamento ideológico, pois, como nos lembra Hall (2003), em sua leitura de Althusser, a ideologia funciona através de repertórios discursivos que já estão aí desde que nascemos, que nos aguardam e nos enovelam em construções discursivas que (re)produzem individuações dos sujeitos. Não se trata simplesmente da existência de ideias nas cabeças das pessoas, mas um atributo de linguagem que terá grande apelo na formação da psique e das próprias escolhas dos indivíduos. Como o enunciado acima referido se localiza dentro de uma cartilha escolar, podemos ver como a escola funciona como local de reforço das instituições hegemônicas produzindo, consequentemente, exclusões. Neste caso, a cartilha não leva em consideração o contingente de famílias negras nos Estados Unidos, que viveriam de maneira diferente e teriam traços étnicos distintos. O reforço aqui é para o modelo de família branca, de olhos azuis.

Retomando o conceito de literatura pós-colonial como essencialmente questionadora e subversiva, percebemos que Morrison, ao definir o protótipo de família 
idealizada, contrapõe esse modelo ao focalizar uma família totalmente destoante de tal padrão. Trata-se da família Breedlove, que se move da zona rural para o centro urbano de Lorain, Ohio. Essa família é extremamente problemática, na medida em que se aparta do modelo de família ideal preconizado pelo American dream. Ademais, as condições precárias de vida e o fato de estarem distantes de sua terra natal contribuíram para as disfunções familiares.

Nessa esfera familiar, Morrison focaliza a personagem Pecola Breedlove, uma menina afro-estadunidense de 11 anos de idade, que vive em um subúrbio da cidade de Ohio, em fins dos anos 1940. Como a grande maioria das crianças de sua minoria étnica, Pecola é extremamente pobre, fruto de um casamento infeliz entre uma empregada doméstica e um alcoólatra.

Seus pais, Cholly e Mrs. Breedlove, brigam com frequência e a negligenciam, o que a deixa muito chateada, pois imagina que se fosse bonita e dotada de belos olhos azuis seria mais amada e sua família mais feliz: If she looked different, beautiful, maybe Cholly would be different, and Mrs. Breedlove too. Maybe they'd say, 'Why, look at pretty-eyes Pecola. We musn't do bad things in front of those pretty eyes (MORRISON, 1970, p. 46) ${ }^{2}$. Além disso, as pessoas de cor branca tecem comentários preconceituosos sobre sua cor e aparência física. Todo o pré-julgamento e exclusão por parte da sociedade levam Pecola ao isolamento, de modo que a menina passa horas se mirando no espelho, tentando descobrir o porquê de sua feiúra, motivo de desprezo por tanta gente.

Em sua inocência, ela acredita que, caso tivesse olhos azuis, sua vida seria muito melhor: ela seria amada pelos pais e, com certeza, seria bonita e aceita por todos. Nesse sentido, torna evidente a influência da ideologia da beleza normativa (branca) sobre a menina. Ou seja, tal pensamento não parte dela própria, na medida em que é a ideologia que interpela os sujeitos. Chauí (1981), ao discorrer sobre o complexo conceito de ideologia, afirma que uma determinada classe se torna hegemônica

[...] não só porque detém a propriedade dos meios de produção e o poder do Estado (isto é, o controle jurídico, político e policial da sociedade), mas ela é hegemônica sobretudo porque suas idéias e valores são dominantes, e mantidos pelos dominados até mesmo quando lutam contra essa dominação (CHAUÍ, 1981, p. 110).

Nessa mesma perspectiva, Althusser (1996) afirma que a Igreja era, no passado, o aparelho ideológico de estado mais influente, pois não só a religião ficava sob seu julgo, mas também a cultura e educação. Com o passar dos anos, a escola também assumiu tal posição de aparelho ideológico. Nesse sentido, Pecola sofreu os efeitos dessa influência quando era ridicularizada e desprezada pela comunidade escolar por sua cor, como seus caracteres étnicos indicassem sua inferioridade frente às outras crianças. Sentindo-se culpada, a menina, ainda sem ter consciência da etnia como forma de estratificação social,

\footnotetext{
${ }^{2}$ Doravante, as referências a The Bluest Eye serão feitas utilizando-se apenas as iniciais do título BE.
} 
indagava-se sobre o que, em suas feições, causava tanto repúdio social: Long hours she sat looking in the mirror, trying to discover the secret of her ugliness, the ugliness that made her ignored or despised at school, by teachers and classmates alike. (BE, p. 34).

Após ter sua casa destruída por um incêndio causado pelo pai bêbado, a família Breedlove é temporariamente separada: assim, o Serviço Social encaminha o irmão de Pecola para a casa de uma família local, sua mãe passa a morar com a família para a qual trabalha e Pecola vai viver na casa da família MacTeer, onde conviverá com as irmãs Claudia e Frieda, crianças que, embora pertencentes à mesma etnia, são filhas de uma família muito mais estruturada do que a sua.

Ali, será extremamente discriminada, pois suas fortes características étnicas causariam desconforto nas próprias meninas de sua etnia, que, na tentativa de se aproximarem do padrão de beleza normativo, tentavam reprimir suas próprias características étnicas. Um exemplo inequívoco dessa atitude é Geraldine, uma negra de classe média que, apesar de ter ascendido socialmente, não se sente aceita pela sociedade devido à sua procedência étnica. Como forma de recusa da sua cor, a personagem rejeita o filho Louis Junior, também negro, enquanto, em patente contraste, demonstra grande adoração por seu gato de olhos azuis. Além disso, rejeita suas características físicas que a distanciam do padrão de feminilidade estadunidense, haja vista sua aversão pelos seus traços físicos e pelos odores de seu corpo. Geraldine não suporta Pecola exatamente porque a menina a faz lembrar de sua origem:

She looked at Pecola. Saw the dirty torn dress, the plaits sticking out on her head, hair matted where the plaits had come undone, the muddy shoes with the wad of gum peeping out from between the cheap soles, the soiled socks, one of which had been walked down into the heel on the shoe. ... She had seen this little girl all of her life. Hanging out of windows over saloons in Mobile, crawling over the porches of shotgun houses on the edges of town, sitting in bus stations holding paper bags and crying to mothers who kept saying 'Shet up!' (BE, p. 71-72).

Para entendermos como alguém discrimina um indivíduo de sua mesma etnia, é necessário a compreensão de que a identidade se confirma através da alteridade e do estranhamento em relação ao outro. Diversos campos do saber têm demonstrado a importância da interação para a própria constituição da identidade do sujeito enquanto ser social. Enquanto estudos em áreas como a Filosofia (Ex: Hegel com sua dialética do Senhor e do Escravo) e a Psicanálise (Ex: Lacan com sua teorização acerca da Fase do Espelho) trouxeram noções importantes sobre a relação com um Outro, com a alteridade, para a consciência de si. Dessa forma, ao apontar Pecola como negra - e, portanto, ratificar sua diferença em relação a ela -, Geraldine se aproximaria do simbolicamente do oposto, isto é, da etnia branca.

No entanto, há outras personagens que, caracterizando o tom subversivo do romance, demonstram resistência à ditadura da beleza normativa. Claudia MacTeer, personagem-narradora de parte do romance, consiste numa espécie de antítese de Pecola. 
Em seus relatos através de flashbacks, Claudia demonstra o quanto odiava as bonecas da época, que eram sempre loiras, de olhos azuis, determinando a ideologia da superioridade branca já nas crianças: Ahhhhh", take off the head, shake out the sawdust, crack the back against the brass bed rail, it would bleat still. The gauze back would split, and I could see the dish with six holes, the secret of the sound. A mere metal roundness (BE, p. 14).

Enquanto Claudia simplesmente desmonta bonecas loiras, de faces rosadas e olhos azuis - o que nos remete ao apelo contemporânea das bonecas Barbie como protótipos de perfeição feminina no Ocidente -, a aspiração máxima de Pecola é ter olhos azuis.

A atriz mirim Shirley Temple, tida como a figura ideal do padrão de beleza da década de quarenta, também era muito criticada pela personagem Cláudia:

Frieda brought her four graham crackers on a saucer and some milk in a blue-and-white Shirley Temple cup. She was a long time with the milk, and gazed fondly at the silhouette of Shirley Temple's dimpled face. Frieda and she had a loving conversation about how cute Shirley Temple was. I couldn't join them in their adoration because I hated Shirley. Not because she was cute, but because she danced with Bojangles, who was my friend, my uncle, my daddy, and who ought to have been soft-shoeing it and chuckling with me. Instead he was enjoying, sharing, giving a lovely dance thing with one of those little white girls whose socks never slid down under their heels. So I said, "I like Jane Withers (BE, p. 12).

Entretanto, para maioria das outras meninas, Shirley Teple era símbolo de tudo que provavelmente muitas delas almejavam ser. Pecola, inclusive, rezava todos os dias por esse milagre que na sua imaginação mudaria sua vida: Each night, without fail, she prayed for blue eyes. Fervently, for a year she had prayed. Although somewhat discouraged, she was not without hope. To have something as wonderful as that happen would take a long, long time (BE, p. 35).

Contudo, Pecola tem seu desejo atendido da maneira mais trágica possível. Em um arroubo de luxúria seu pai comete incesto e Pecola engravida. Sua mãe se refugia no emprego de servente para uma família rica, de gente loira e de olhos azuis, onde encontra toda a paz e sentido que sua pobreza não pode lhe oferecer. Pecola aprofunda seu processo de loucura e termina criando um mundo só seu, no qual ela possui olhos azuis e, portanto, é amada.

Quando do nascimento de seu bebê, que nasce morto, ela é abandonada por todos e enlouquece. O final do romance mostra Pecola, que agora se vê com belíssimos olhos azuis, conversando com "sua amiga", também chamada Pecola, que enxerga seus olhos azuis e os elogia. A esta altura cabe acentuar que o título do romance contém a palavra "bluest", que sugere uma pluralidade de sentidos. Primeiramente, podemos tomar o sentido literal e interpretar The Bluest Eye como $O$ olho mais azul, remetendo à vontade da menina de ter olhos azuis. Podemos também recair sobre o outro sentido do abjetivo blue na língua inglesa, a referência à tristeza, interpretando o título - que, em seu jogo com a linguagem, constitui mais um aspecto subversivo da literatura pós-colonial - como "o olho mais triste". 
E em terceiro lugar, podemos pensar que a palavra nos remete ao próprio "blues" como expressão musical negra, aquilo que mais caracteriza a cultura dos afro-descendentes norteamericanos.

Neste sentido, the bluest eye nada teria a ver com a cor dos olhos, sendo, portanto, uma referência irônica àquilo que distinguia brancos e negros. Esse parece ser o sentido mais forte do título, uma vez que não se restringe ao registro da cor dos olhos ou da pele, mas à cultura como um todo. Ademais, podemos considerar, a partir desta exposição, que o romance de Toni Morrison pode ser lido como um texto crítico em relação ao próprio feminismo, que muitas vezes exclui de sua agenda a situação de mulheres negras. Nesse sentido, é pertinente a colocação de Dubey:

The presence that defines black feminine characters in the novel as deficient is represented not by the black man but the white woman. (...) Each expression of black feminine desire, whether Pecola's longing for blue eyes, Frieda's love of Shirley Temple, Claudia's hatred of white dolls, Maureen's adoration of Betty Grable, or Pauline's of Jean Harlow, takes the white woman as its object (1994 p. 39-40).

No entanto, como no romance nem todas as personagens afro-estadunidenses aderem ou se submetem ao padrão normativo de feminilidade, podemos afirmar que o romance desestabiliza a ordem social convencional ao abordar a inadequação de certas personagens femininas às normas socialmente construídas. Portanto, "desmascara" o ideal de "beleza americana" ao trazer à luz seu aspecto desumano e impiedoso para com a alteridade.

Dessa forma, The Bluest Eye, em sua representação dos efeitos catastróficos da ideologia da beleza branca sobre uma etnia cujos caracteres físicos não se enquadram nesse padrão, constitui uma crítica contundente ao processo ideológico de controle e regulação dos sujeitos sociais, especialmente das mulheres, as quais o romance focaliza.

\section{5)Considerações finais}

Em The Bluest Eye, Morrison desperta no leitor um novo olhar sobre a causa negra e uma visão realista sobre os problemas enfrentados pela sociedade negra na primeira metade do século XX. A influência da ideologia, fortemente marcada em todo o romance, apresenta valores calcificados em uma sociedade capitalista em pleno desenvolvimento, permeada por conceitos alienantes, discriminatórios e intolerantes. Nesse sentido, The Bluest Eye sinaliza que escapar da ideologia, especificamente no tocante à ditadura da beleza branca, constitui uma tarefa árdua, mas não impossível de ser realizada, ao menos parcialmente. Prova disso é o fato de que a narradora, Claudia, tornou-se uma mulher forte e independente. No entanto, não consegue resistir aos encantos de Shirley Temple, a estrela mirim que representa, na narrativa, o padrão de beleza feminina ideologicamente constituído. 
Podemos considerar The Bluest Eye, enquanto primeiro livro de Morrison, como uma primeira tentativa da autora em promover a construção da identidade cultural dos afroestadunidenses, uma vez que tal temática é retomada em diversos livros posteriores da escritora afro-americana, tais como Beloved, Paradise e outros. Morrison mostra, na caracterização de uma menina negra e pobre, como a ideologia influencia a sociedade e exerce impacto sobre a vida dos sujeitos.

Outro ponto observado na obra de Morrison é a busca pela identidade da minoria étnica de origem africana nos Estados Unidos. Com a hegemonia da etnia branca, os negros se mantinham à sombra, em um sistema que marginalizava a diferença. Contudo, Morrison procura construir uma representação de identidade dos afro-estadunidenses em uma época de grande tensão étnica. Com isso, ao colocar em evidência a etnia afro-descendente, exprime, enquanto aquela que fala pelos subalternos que não têm voz, as emoções, sofrimentos e angústias de uma coletividade que só poderia ser tão bem retratada pela perspectiva de alguém que viveu a mesma situação.

Apesar de o livro ter sido escrito em meados da década de 1960, o tempo da narrativa remontar aos anos 1940 e os eventos narrados terem como pano de fundo o contexto histórico referente à primeira metade do século $\mathrm{XX}$, seus temas continuam atuais. Vemos que a ideologia racial que vigorava na época ainda se mantém robusta em uma sociedade ainda excludente. Essa consciência do sistema traz conseqüências drásticas, como o enlouquecimento de Pecola. Prova-se, assim, que somos adestrados por ideologias sem nos darmos conta, porque, caso refletíssemos, enlouqueceríamos, conforme aconteceu à personagem Pecola.

Nesse sentido, este trabalho constitui uma reflexão a partir do próprio (per)curso realizado ao longo de anos pelos autores do texto em questão, visando possibilitar cada vez mais reflexões acerca de questões relativas a gênero, etnia e ideologia e a relação de tais categorias com o texto de Morrison à luz dos Estudos Pós-Coloniais e dos Estudos de Gênero, abrindo veredas para a continuidade e o aprimoramento da pesquisa aqui esboçada em trabalhos mais detalhados, a serem desenvolvidos futuramente por outros autores, a espelho de um dos desejos de Foucault que este alimentava em relação às obras que escrevia: "Não escrevo um livro para que seja o último; escrevo um livro para que outros sejam possíveis - não necessariamente escritos por mim” (FOUCAULT, 1971, p. 25-26).

\section{Referências:}

ALTHUSSER, L. Ideologia e aparelhos ideológicos de Estado: notas para uma investigação. In: ZIZEK, S. (Org.). Um mapa da ideologia. Rio de Janeiro: Contraponto, 1996, p. 105-142. 
ASHCROFT, B. GRIFFITHS, G., TIFFIN, H. The Empire Writes Back. $2^{\mathrm{a}}$ ed. London, New York: Routledge, 2002.

BEAUVOIR, S. O segundo sexo. II a experiência vivida. São Paulo: Difusão Européia do Livro, 1967.

BONNICI, T. O pós-colonialismo e a literatura: estratégias de leitura. Maringá: EDUEM, 2000 .

BROGAN, H. The Penguin History of the United States of America. London: Penguin, 1985.

BUTLER, J. Gender Trouble: Feminism and the Subversion of Identity. New York: Routledge, 1990.

CEVASCO, M. E. Estudos Culturais X estudos Literários. Letras \& letras: Revista do Instituto de Letras e Lingüística da UFU, 17 (1e 2), p. 45-54, jan./dez. 2001.

CHAUÍ, Marilena. O que é ideologia. São Paulo: Brasiliense, 1981.

DE LAURETIS, T. Technologies of Gender. Bloomington: Indiana University Press, 1987.

DEL PRIORE, M. Histórias do cotidiano. São Paulo: Contexto, 2001.

DUBEY, M. Black Women Novelists and the National Aesthetic. Bloomington, Indianapolis: Indiana University Press, 1994.

FOUCAULT, M. O homem e o discurso. Rio de Janeiro: Tempo Brasileiro, 1971.

FOUCAULT, M. Power/Knowledge. Selected Interviews and Other Writings. 19721977. Ed. Colin Gordon. New York: Pantheon, 1980.

HALL, Stuart. Significação, representação, ideologia: Althusser e os debates pósestruturalistas. In: HALL, S. Da diáspora: identidades e mediações culturais. Trad. Adelaine LaGuardia Resende et al. Belo Horizonte: editora da UFMG; Brasília: UNESCO no Brasil, 2003, p. 160-198.

GILBERT, S. M. \& GUBAR, S. The Madwoman in the Attic: the Woman Writer and the Nineteenth-Century Literary Imagination. London: YaleUniversity Press, 2000. 
LARROSA, Jorge, KOHAN, Walter. Apresentação da coleção. In: RANCIÈRE, Jaques. O mestre ignorante: Cinco lições sobre a Emancipação Intelectual. Belo Horizonte: Autêntica, 2002, p. 1-38.

MARODIN, M. As relações entre o homem e a mulher na atualidade. In: STREY, M. N. (Org.). Mulher: estudos de gênero. São Leopoldo: Editora da Unisinos, 1997, p. 9-18.

McCLINTOCK, A. The Angel of Progress: Pitfalls of the term 'post-colonialism'. Social Text, Durham, v. 31-32, n. 01, p. 84-98, 1992.

MORRISON, T. The Bluest Eye. New York. Washington Square Press. 1970.

NEVES, Cleiton Ricardo das; ALMEIDA, Amélia Cardoso de. O papel da mulher intellectual na libertação da subalternidade de gênero no mundo pós-colonial. Em tempo de histórias, Brasília, n. 25, p. 71-86, ago-dez 2014.

RIGNEY, Barbara. The Voices of Toni Morrison. Columbia: Ohio State University Press, 1991.

SILVEIRA, E. L. (Des)construções acerca do imaginário de uma língua homogênea: consequências e discursivizações de um mito. Web-revista Linguagem, educação e memória, Campo Grande, MS, n. 04, p. 1-10, julho de 2013.

TOLLER GOMES, H. Crítica pós-colonial em questão. Revista Z Cultural, Rio de Janeiro, vol. 03, n. 01, p. 1-12, 2006.

WOODWARD, K. Identidade e diferença: uma introdução teórica e conceitual. In: SILVA, T. T. (Org.). Identidade e diferença: A perspectiva dos estudos culturais. Petrópolis: Vozes, 2000, p. 7-72.

WOOLF, V. A room of one's own. Harmondsworth: Penguin Books, 1970. 